\title{
Uji Daya Hasil Empat Galur Padi Generasi ke Empat di Lahan Politeknik Negeri Lampung
}

\section{Power Test Result of Four Rice of Fourth Generation in Lampung State Polytechnic Area}

\author{
Ana Tri Lestari, Jaenudin Kartahadimaja*, dan Nurman Abdul Hakim \\ Program Studi Teknologi Perbenihan Polinela \\ Jl. Soekarno-Hatta No.10, Rajabasa Bandar Lampung \\ *E-mail : jaenudinkartahadimaja@gmail.com
}

\begin{abstract}
The largest food commodity in Indonesia is rice (Oryza sativa), because rice is the main food source for most of Indonesia's population. Rice productivity can be increased, among others through innovation of high yield rice varieties, resistant to biotic and abiotic stress, and have good rice quality. The effort to form high yielding high yielding varieties requires several stages, one of which is power yield test. This research was conducted to obtain potential yield data from the four strains tested in the fourth generation. The strains studied were MS1, MS2, MS3 and ChM strains, with two varieties of varieties, namely Ciherang and Cilamaya varieties. This study used per-line planting method and conducted with Randomize Completly Block Design (RCBD). Observations were made on selected individual plants as samples. The variables observed were maximum plant height, maximum number of shoots, number of productive shoots, flowering age, harvest age, panicle length, number of grain per panicle, amount of unhulled grain per panicle, total grain per panicle, weight 1,000 grains, Clumps and grain yield per hectare. The data were analyzed by using variance, and if there was any difference between treatments, then the data will be tested further with Least Significant Different (LSD) on stage 5\%.. Based on the observation and test, the result of production of each strain is MS1 strain of 7.24 ton.ha-1, MS2 strain of 6.06 ton.ha-1, MS3 strain of 6.29 ton.ha-1, and ChM strain of 6.01 ton.ha-1.
\end{abstract}

Keywords: Strain, Rice, Results power test.

Disubmit : 23 Agustus 2017, Diterima : 01 Desember 2017, Disetujui :08 Desember 2017

\section{PENDAHULUAN}

Menurut Badan Pusat Statistik Provinsi Lampung (2016), selama periode tahun 2011 - 2015, produksi padi di Provinsi Lampung mengalami peningkatan. Produksi padi terendah terjadi tahun 2011 yaitu 2,94 juta ton gabah kering giling (GKG) dan tertinggi tahun 2015 yang mencapai 3,64 juta ton gabah kering giling (GKG). Secara rata-rata produksi benih padi mengalami peningkatan 5,52 persen per tahun atau sekitar 0,18 juta ton gabah kering giling. Kenaikan produksi padi pada periode tersebut relatif bervariasi dimana kenaikan produksi terendah terjadi tahun 2013 yaitu 0,10 juta ton GKG atau naik 3,42 persen dibandingkan dengan tahun sebelumnya. Sementara kenaikan produksi tertinggi terjadi tahun 2015 yaitu 0,32 juta ton GKG atau naik 9,69 persen dibandingkan dengan tahun sebelumnya. Kondisi ini disebabkan oleh kenaikan luas panen seluas 58,54 ribu hektar (9,02 persen) dan produktivitas sebesar 0,31 kw.ha-1 $(0,61$ persen). 
Produktivitas padi dapat ditingkatkan, antara lain melalui inovasi perakitan varietas-varietas padi yang berdaya hasil tinggi, tahan terhadap cekaman biotik dan abiotik, serta memiliki kualitas beras yang baik (Syuriani dkk., 2013). Upaya pembentukan varietas unggul berdaya hasil tinggi membutuhkan beberapa tahap salah satunya pengujian daya hasil. Tahap ini dibutuhkan untuk menguji daya hasil galur-galur padi yang telah ada, kemudian diseleksi untuk dikembangkan menjadi varietas (Rahmah dan Aswidinnoor, 2013). Sehingga, penelitian ini dilakukan uji daya hasil terhadap 4 galur padi baru generasi ke-4, yaitu galur MS1, MS2, MS3, dan ChM.

\section{METODE PENELITIAN}

Penelitian ini dilaksanakan pada bulan Januari - Mei 2016 dan dilaksanakan di lahan sawah Politeknik Negeri Lampung. Bahan yang digunakan dalam penelitian ini terdiri atas 4 galur padi generasi ke-empat rakitan Politeknik Negeri Lampung yaitu galur hasil persilangan antara varietas Cilamaya Muncul dengan Situbagendit segregan 1 (MS1), galur hasil persilangan antara varietas Cilamaya Muncul dengan Situbagendit segregan 2 (MS2), galur hasil persilangan antara varietas Cilamaya Muncul dengan Situbagendit segregan 3 (MS3), dan galur hasil persilangan antara varietas Ciherang dengan Cilamaya Muncul (ChM), serta dua varietas pembanding yaitu varietas Ciherang dan Cilamaya Muncul.

Rancangan penanaman dalam penelitian ini adalah masing-masing galur dan varietas ditanam dalam satu plot yang berbeda dengan luas per plot yaitu 3,56 $\mathrm{m}^{2}$. Pengambilan sampel dilakukan secara acak kelompok, per plot terdiri dari 3 ulangan dan masing-masing ulangan terdiri dari 5 sampel. Data dianalisis dengan menggunakan sidik ragam. Jika ada perbedaan diantara perlakuan, maka data akan diuji lebih lanjut dengan uji BNT pada taraf nyata $5 \%$.

Benih padi disemai terlebih dahulu di lahan kering dengan cara ditabur rata. Lahan diolah dengan menggunakan cangkul, kemudian lahan sawah dilumpurkan dengan cara digaru sampai rata. Penanaman dilakukan pada saat bibit berumur 24 Hari Setelah Semai (HSS). Bibit di transplanting dipetakan yang luasnya $3,56 \mathrm{~m}^{2}$ per perlakuan. Setiap lubang tanam ditanami satu bibit sedalam 3-4 cm dengan jarak tanam $25 \mathrm{~cm} \mathrm{x}$ $25 \mathrm{~cm}$. Penyulaman dilakukan pada 7 Hari Setelah Tanam (HST) dengan bibit dari galur dan umur yang sama.

Pemeliharaan tanaman meliputi pemupukan, pengairan, penyiangan, dan pengendalian hama dan penyakit. Variabel yang diamati yaitu tinggi tanaman maksimum, jumlah tunas maksimum, jumlah tunas produktif, umur berbunga, umur panen, panjang malai, jumlah gabah isi per malai, jumlah gabah hampa per malai, jumlah gabah total per malai, bobot 1.000 butir, bobot gabah per rumpun dan hasil gabah per hektar.

\section{HASIL DAN PEMBAHASAN}

Empat galur padi yang diuji masing-masing memiliki tinggi tanaman yang bervariasi (Tabel 1.). Dari ke-empat galur padi yang diuji memiliki rerata tinggi tanaman maksimum lebih rendah dari varietas Cilamaya Muncul. Syuriani dkk., (2013), menyatakan bahwa fenotipe tanaman padi yang batangnya rendah akan memberikan keuntungan dibandingkan dengan tanaman padi yang fenotipe batangnya tinggi. Tanaman padi yang fenotipe batangnya rendah akan lebih tahan rebah/roboh jika terhembus angin, terutama pada saat padi masuk fase pengisian buah. Oleh karena itu Fenotipe tanaman padi yang batangnya rendah lebih disukai oleh petani, karena resiko akan mengalami kerusakan tanaman akibat rebah bisa dihindari.

Menurut Abdullah (2009), sifat padi tipe baru yang mendukung potensi hasil tinggi adalah anakan sedang tapi produktif semua (12-18 batang). Ke-empat galur yang diuji memiliki rerata jumlah tunas produktif yang sedang yaitu berkisar antara 13,40 - 15,20 tunas. Galur MS1, MS2, dan ChM memiliki rerata jumlah tunas maksimum yang lebih rendah dibandingkan dengan varietas Ciherang dan Cilamaya Muncul. Galur MS3 memiliki rerata jumlah tunas maksimum yang tidak berbeda nyata dengan varietas Ciherang. Tiga galur padi yang memiliki rerata jumlah tunas produktif yang setara dengan varietas Cilamaya Muncul yaitu galur MS1, MS2, dan MS3. Ke-empat galur padi yang diuji memiliki rerata jumlah tunas produktif lebih 
sedikit dibandingkan dengan varietas Ciherang, yaitu galur MS1 14,27 tunas tiap rumpun, MS2 13,73 tunas tiap rumpun, galur MS3 15,20 tunas tiap rumpun, dan galur ChM 13,40 tunas tiap rumpun.

Tabel 1. Rerata tinggi tanaman maksimum, jumlah tunas maksimum dan jumlah tunas produktif

\begin{tabular}{lllcccc}
\hline No & Galur/Varietas & $\begin{array}{c}\text { Tinggi } \\
\text { Tanaman } \\
\text { Maksimum } \\
\text { (cm) }\end{array}$ & $\begin{array}{c}\text { Jumlah } \\
\text { Tunas } \\
\text { Maksimum } \\
\text { (batang) }\end{array}$ & $\begin{array}{c}\text { Jumlah } \\
\text { Tunas } \\
\text { Produktif } \\
\text { (batang) }\end{array}$ & $\begin{array}{c}\text { Umur } \\
\text { Berbunga } \\
\text { (Hari) }\end{array}$ & $\begin{array}{c}\text { Umur Panen } \\
\text { (Hari) }\end{array}$ \\
\hline 1 & MS1 & $124,13 \mathrm{~b}$ & $17,07 \mathrm{c}$ & $14,27 \mathrm{bc}$ & $76,93 \mathrm{~cd}$ & $106,67 \mathrm{~b}$ \\
2 & MS2 & $113,40 \mathrm{c}$ & $16,27 \mathrm{c}$ & $13,73 \mathrm{bc}$ & $78,00 \mathrm{bc}$ & $109,00 \mathrm{a}$ \\
3 & MS3 & $120,73 \mathrm{~b}$ & $21,67 \mathrm{a}$ & $15,20 \mathrm{bc}$ & $74,13 \mathrm{e}$ & $99,13 \mathrm{~d}$ \\
4 & ChM & $111,53 \mathrm{c}$ & $15,47 \mathrm{c}$ & $13,40 \mathrm{c}$ & $80,07 \mathrm{a}$ & $109,07 \mathrm{a}$ \\
5 & Ciherang & $113,07 \mathrm{c}$ & $21,40 \mathrm{ab}$ & $17,53 \mathrm{a}$ & $79,00 \mathrm{ab}$ & $108,00 \mathrm{a}$ \\
6 & Cilamaya Muncul & $129,40 \mathrm{a}$ & $19,33 \mathrm{~b}$ & $15,67 \mathrm{ab}$ & $76,00 \mathrm{~d}$ & $103,73 \mathrm{c}$ \\
\hline
\end{tabular}

Keterangan: Angka-angka yang diikuti oleh huruf yang sama dalam satu kolom yang sama menunjukkan tidak berbeda berbeda nyata pada taraf 5\% Uji BNT.

Kecepatan umur berbunga mempengaruhi kecepatan umur panen. Semakin cepat umur berbunga maka semakin cepat umur masak. Pada tabel 1, menunjukkan bahwa galur MS3 memiliki umur berbunga dan umur panen yang lebih cepat dibandingkan galur MS1, MS2, ChM dan dua varietas pembandingnya. Menurut Balai Besar Penelitian Tanaman Padi (2015), umur panen padi dikategorikan sebagai berikut : Umur dalam (>151 Hari Setelah Semai/HSS), sedang (125 - 150 HSS), genjah (105 - 124 HSS), sangat genjah (90 - 104 HSS) dan ultra genjah (<90 HSS). Galur MS1, MS2 dan ChM memiliki kriteria umur panen genjah dengan umur panen berturut-turut 106,67 HSS, 109,00 HSS dan 109,07 HSS, sedangkan galur MS3 memiliki kriteria umur panen yang sangat genjah yaitu 99,13 HSS.

Tabel 2. Rerata panjang malai, jumlah gabah per malai, jumlah gabah isi per malai, dan jumlah gabah hampa per malai

\begin{tabular}{|c|c|c|c|c|c|}
\hline No & Galur/Varietas & $\begin{array}{ll}\text { Panjang } & \text { Malai } \\
(\mathrm{cm}) & \end{array}$ & $\begin{array}{l}\Sigma \text { IGabah/malai } \\
\text { (butir) }\end{array}$ & $\begin{array}{l}\text { इGabah Isi/malai } \\
\text { (butir) }\end{array}$ & $\begin{array}{l}\Sigma \text { Gabah } \\
\text { Hampa/malai } \\
\text { (butir) }\end{array}$ \\
\hline 1 & MS1 & $25,55 \mathrm{bcd}$ & $240,00 \mathrm{a}$ & $151,47 \mathrm{a}$ & $88,53 \mathrm{a}$ \\
\hline 2 & MS2 & $26,27 \mathrm{a}$ & $194,47 \mathrm{~b}$ & $127,40 \mathrm{bc}$ & $67,07 \mathrm{~b}$ \\
\hline 3 & MS3 & $25,00 \mathrm{~d}$ & $178,93 \mathrm{~b}$ & $90,40 \mathrm{~d}$ & 88,53 a \\
\hline 4 & $\mathrm{ChM}$ & $25,73 \mathrm{abc}$ & $186,13 \mathrm{~b}$ & $122,93 \mathrm{c}$ & $63,20 \mathrm{~b}$ \\
\hline 5 & Ciherang & $25,28 \mathrm{~cd}$ & $193,53 \mathrm{~b}$ & $131,47 \mathrm{bc}$ & $62,07 \mathrm{~b}$ \\
\hline 6 & Cilamaya Muncul & $26,09 \mathrm{ab}$ & $184,11 \mathrm{~b}$ & $144,22 \mathrm{ab}$ & $39,89 \mathrm{c}$ \\
\hline
\end{tabular}

Keterangan: Angka-angka yang diikuti oleh huruf yang sama dalam satu kolom yang sama menunjukkan tidak berbeda nyata pada taraf $5 \%$ Uji BNT.

Komponen panjang malai merupakan faktor pendukung utama untuk potensi hasil karena semakin panjang malainya berpeluang menghasilkan gabah lebih banyak (Siregar, 1998 dalam Kustera, 2008). Haryadi (2006) dalam Rahmah dan Aswidinnoor (2013), menyatakan bahwa panjang malai dikelompokkan menjadi tiga kelas yaitu : malai pendek $<20 \mathrm{~cm}$, malai sedang $20-30 \mathrm{~cm}$, dan malai panjang $>30 \mathrm{~cm}$. Galur MS2 memiliki rerata panjang malai yang berbeda nyata dengan galur MS1 dan MS3 (Tabel 2). Galur MS2 memiliki rerata panjang malai yang lebih panjang dibandingkan dengan varietas Ciherang dan setara dengan varietas 
Cilamaya Muncul, yaitu 26,27 cm. Terdapat tiga galur padi yang memiliki rerata panjang malai yang setara dengan varietas Ciherang yaitu galur MS1, MS3 dan ChM.

Malai yang panjang belum tentu menghasilkan gabah yang banyak, seperti galur MS2 meskipun memiliki panjang malai tertinggi akan tetapi rerata jumlah gabah per malai yang dihasilkan lebih rendah daripada galur MS1. Malai yang panjang ternyata letak gabahnya jarang-jarang (tidak rapat). Rerata jumlah gabah per malai pada galur MS1 berbeda nyata dengan galur MS2, MS3, ChM, dan dua varietas pembandingnya. Galur MS1 memiliki rerata jumlah gabah per malai lebih tinggi dibandingkan dengan galur lainnya dan dua varietas pembandingnya yaitu 240,00 butir (Tabel 2).

Menurut Satoto dan Suprihatno (1996) dalam Kustera (2008) potensi genetik karakter jumlah gabah bernas per malai yang dihasilkan akan lebih baik jika ditopang dengan kondisi lingkungan yang cocok dalam perkembangan galur suatu tanaman. Kondisi lingkungan yang dimaksud adalah keadaan iklim dengan pencahayaan yang mencukupi untuk berfotosintesis, unsur hara yang memadai serta air yang cukup pada saat pengisian biji. Faktor yang membatasi fotosintesis dapat berakibat berkurangnya pengisian biji pada tanaman padi.

Rerata jumlah gabah isi per malai pada galur MS1 tidak berbeda nyata dengan varietas Cilamaya Muncul dan MS3. Terdapat dua galur yang memiliki rerata jumlah gabah isi per malai yang setara dengan varietas Ciherang, yaitu galur M2 dan ChM. Galur MS3 memiliki rerata jumlah gabah isi per malai yang lebih rendah daripada galur lainnya dan dua varietas pembandingnya, yaitu 90,40 butir. Terdapat dua galur yang memiliki rerata jumlah gabah hampa per malai yang setara dengan varietas Ciherang yaitu galur MS2 dan ChM. Rerata jumlah gabah hampa per malai pada varietas Cilamaya Muncul lebih rendah daripada ke-empat galur yang diuji yaitu 39,89 butir.

Bobot 1.000 butir gabah pada galur MS1 tidak berbeda nyata dengan varietas Ciherang. Galur MS1 memiliki bobot 1.000 butir gabah lebih rendah daripada galur MS2, MS3, ChM dan varietas Cilamaya Muncul, yaitu 23,40 g. Terdapat tiga galur padi yang memiliki bobot 1.000 butir gabah yang setara dengan varietas Cilamaya Muncul, yaitu galur MS2, MS3 dan ChM. Menurut Abdullah (2009), sifat padi tipe baru yang mendukung potensi hasil tinggi adalah memiliki bobot 1.000 butir antara 25 - 26 g. Galur MS2, MS3 dan ChM memiliki bobot seribu butir antara 25 - 25,60 g atau setara dengan padi tipe baru. Prajitno dkk., (2006) dalam Nurhidayah (2013), menyatakan bahwa makin tinggi berat 1.000 butir gabah tidak selalu diikuti dengan hasil yang tinggi. Hal ini ditunjukan pada galur MS3 yang memiliki bobot 1.000 butir tinggi akan tetapi hasil produksinya rendah (Tabel 3).

Tabel 3. Rerata bobot 1.000 butir gabah, hasil gabah per rumpun, dan hasil gabah per hektar

\begin{tabular}{llccc}
\hline No & Galur/Varietas & $\begin{array}{c}\text { Bobot 1.000 Butir } \\
\text { Gabah }(\mathbf{g})\end{array}$ & $\begin{array}{c}\text { Hasil Gabah Per } \\
\text { Rumpun }(\mathbf{g})\end{array}$ & $\begin{array}{c}\text { Hasil Gabah Per } \\
\text { Hektar (ton) }\end{array}$ \\
\hline 1 & MS1 & $23,40 \mathrm{c}$ & $45,27 \mathrm{a}$ & $7,24 \mathrm{a}$ \\
2 & MS2 & $25,00 \mathrm{ab}$ & $37,87 \mathrm{c}$ & $6,06 \mathrm{c}$ \\
3 & MS3 & $25,60 \mathrm{a}$ & $39,33 \mathrm{bc}$ & $6,29 \mathrm{bc}$ \\
4 & ChM & $25,13 \mathrm{ab}$ & $37,60 \mathrm{c}$ & $6,01 \mathrm{c}$ \\
5 & Ciherang & $23,73 \mathrm{bc}$ & $44,53 \mathrm{a}$ & $7,12 \mathrm{a}$ \\
6 & Cilamaya Muncul & $25,14 \mathrm{ab}$ & $41,40 \mathrm{~b}$ & $6,62 \mathrm{~b}$
\end{tabular}

Keterangan: Angka-angka yang diikuti oleh huruf yang sama dalam satu kolom yang sama menunjukkan tidak berbeda nyata pada taraf $5 \%$ Uji BNT.

Menurut Aguriansyah (2014) hasil gabah per rumpun berkorelasi kuat dengan hasil gabah per hektar. Semakin tinggi jumlah gabah per rumpun yang dicapai maka semakin tinggi juga nilai hasil gabah per hektar. Hasil gabah per rumpun pada galur MS1 tidak berbeda nyata dengan varietas Ciherang. Galur MS1 memiliki 
rerata hasil gabah per rumpun tertinggi dibandingkan dibandingkan dengan galur MS2, MS3, dan ChM yaitu 45,27 g/rumpun. Galur MS2, MS3, dan CHM memiliki hasil gabah per rumpun yang lebih rendah daripada varietas Ciherang. Terdapat satu galur padi yang memiliki hasil gabah per rumpun yang setara dengan varietas Cilamaya Muncul, yaitu galur MS3.

\section{KESIMPULAN}

Empat galur yang diuji memiliki potensi hasil yang berbeda-beda, galur MS1 memiliki potensi hasil sebesar 7,24 ton.ha ${ }^{-1}$, galur MS2 6,06 ton.ha- ${ }^{-1}$, galur MS3 6,29 ton.ha ${ }^{-1}$, dan galur ChM 6,01 ton.ha ${ }^{-1}$. Galur MS1 memiliki potensi hasil yang paling tinggi dibandingkan dengan galur lainnya terutama dari varietas Cilamaya Muncul. .

\section{DAFTAR PUSTAKA}

Abdullah, Buang. 2009. Perakitan dan Pengembangan Varietas Padi Tipe Baru. Balai Besar Penelitian Tanaman Padi.

Aguriansyah, Ista. 2014. Seleksi Sembilan Galur Padi (Oryza sativa) Generasi Ke-tiga Rakitan Politeknik Negeri Lampung. Skripsi. Jurusan Budidaya Tanaman Pangan. Program Studi Teknologi Perbenihan. Politeknik Negeri Lampung. Lampung.

Badan Pusat Statistik Provinsi Lampung. 2016. Produksi Tanaman Padi Provinsi Lampung 2011-2015. Katalog BPS. Lampung.

Balai Besar Penelitian Tanaman Padi. 2015. Klasifikasi Umur Padi. Badan Penelitian dan Pengembangan Pertanian. Kementerian Pertanian.

Kustera, awang. 2008. Keragaman Genotipe dan Fenotipe Galur-Galur Padi Hibrida Di Desa Kahuman, Polanharjo, Klaten. Skripsi. Jurusan/Program Studi Agronomi. Fakultas Pertanian. Universitas Sebelas Maret. Surakarta.

Nurhidayah, Siti. 2013. Uji Daya Hasil Pendahuluan Generasi F5 Padi Tipe Baru Turunan Tiga Kombinasi Persilangan. Skripsi. Departemen Agronomi Dan Hortikultura. Fakultas Pertanian. Institut Pertanian Bogor. Bogor.

Rahmah, R., dan H. Aswidinnoor. 2013. Uji Daya Hasil Lanjutan 30 Galur Padi Tipe Baru Generasi F6 Hasil dari 7 Kombinasi Persilangan. Bul. Agrohorti 1 (4) : 1 - 8 (2013).

Syuriani, E.E., R. Wentasari, dan J. Kartahadimaja. 2013. Uji Daya Hasil Sepuluh Galur Baru Tanaman Padi (Oryza Sativa L.) Rakitan Politeknik Negeri Lampung. Jurnal Pertanian Penelitian Terapan. 13 (3): 174-179. 